\title{
Socio-Political Imaginings of the Kolkata Maidan
}

\author{
Shreyasi Pal \\ BMS School of Architecture, Bangalore, India \\ shrevasi.bmssa@gmail.com \\ shreyasipal@bmssa.ac.in
}

\author{
Draft paper presented at \\ METUDSYMP2016: DESIGNING URBAN DESIGN: TOWARDS A HOLISTIC PERSPECTIVE \\ http://mud.arch.metu.edu.tr/metudsymp2016-2/
}

\begin{abstract}
The legacy of colonial spatial hegemony in Kolkata is investigated here with focus on the idea of public space particularly, the open maidan, defined by predominantly colonial buildings. This former centrepiece of British spatial expression of authority and pomp is appropriated by diverse uses but the edges can be read as a built record of the city's tryst with colonial rule for two centuries. Evolving from a strictly Palladian palette to a more accommodating Imperial Indo-Saracenic, the continuity of colonial vocabulary is only rarely broken by modern buildings. Parallel situations in other British colonies e.g. the padang in Singapore, have undergone considerable redefinition and re-articulation, often consciously undermining the erstwhile hegemonic position. The paper would trace the ambivalent image of the maidan over the years, to uncover, albeit partially, the patterns to which the colonial, post-colonial and even the neo-liberal State limits itself in imagining this heterogeneous space. The evolving socio-political imagination of the maidan and in that the cityscape would be traced on the basis of how media has captured it at critical historical junctures, the samples varying across time and across media. Maidan as a backdrop of riots, rallies and atrocious human sufferings in the wake of the Partition of India would be captured from newspaper clippings and narratives. Post-independence nation coming to terms with modernization and subsequent characterization of the maidan as a site for civic unrest, a first of a kind public space for sports clubs, picnics, fairs- an embodiment of personal freedom- the urban other- would be understood from stills from Satyajit Ray's Apu Trilogy and the Calcutta Trilogy. The attempt here would be to look for broader patterns of postcolonial urbanism by specific focus on evolving socio-political re-imaginings of colonial urban public spaces.
\end{abstract}

Keywords: Kolkata; colonial; public space; aesthetics 


\title{
Socio-Political Imaginings of the Kolkata Maidan
}

\author{
Shreyasi Pal \\ BMS School of Architecture, Bangalore, India
}

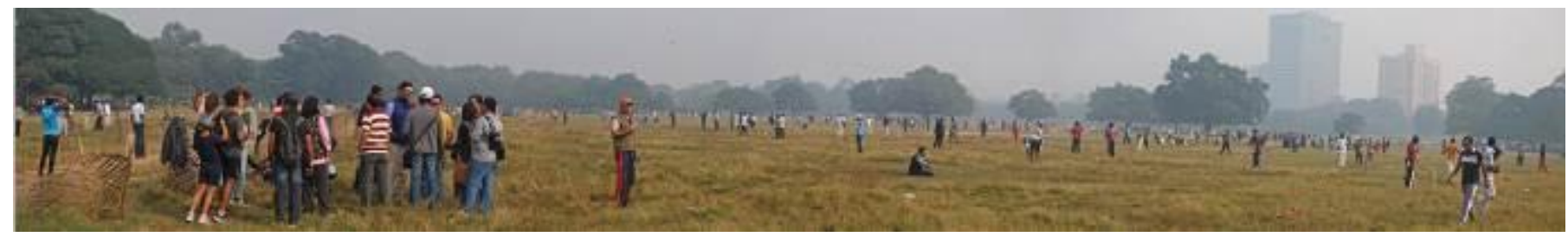

Figure 1. Kolkata maidan as a popular public open space appropriated by people from all walks of life (source: by Rangan Datta under CC 4.0)

\section{Transformation of the Kolkata Maidan}

To the ordinary citizen of Kolkata the maidan also goes by the name gorher maath (গড়ের মাঠ), what roughly translates as the fort grounds. Fort William was erected as a British defense stronghold about two centuries ago and now stations the Eastern Zone High Command of the Indian Army. The maidan today is a welcome expanse of green in a bursting megalopolis with a profusion of activities - fairs, sports and recreational clubs, landscaped gardens and dotted with various commemorative statues, minars, the Eden Gardens Cricket stadium and even the grandiose Victoria Memorial Hall. The word maidan today, brings to mind Kiev Maidan square or Cairo's Maidan Al-Tahir. Kolkata maidan has been and still is a common site for political gatherings, protests and demonstrations.

Though originally an Eastern spatial typology, the colonial rulers applied the spatial device of a maidan as a segregating open space to propagate their sovereignty in foreign soil. Historiography of urban public space in India indicates complex overriding of the concepts of private, civic and public in the indigenous subconscious. In the years leading up to the struggle for independence, the Enlightened middle class, first through a spiritual domain and then as a political activity, constructed the idea of Indian nationalism amidst the heterogeneous colonial subjects of the subcontinent. The colonial introduction of a

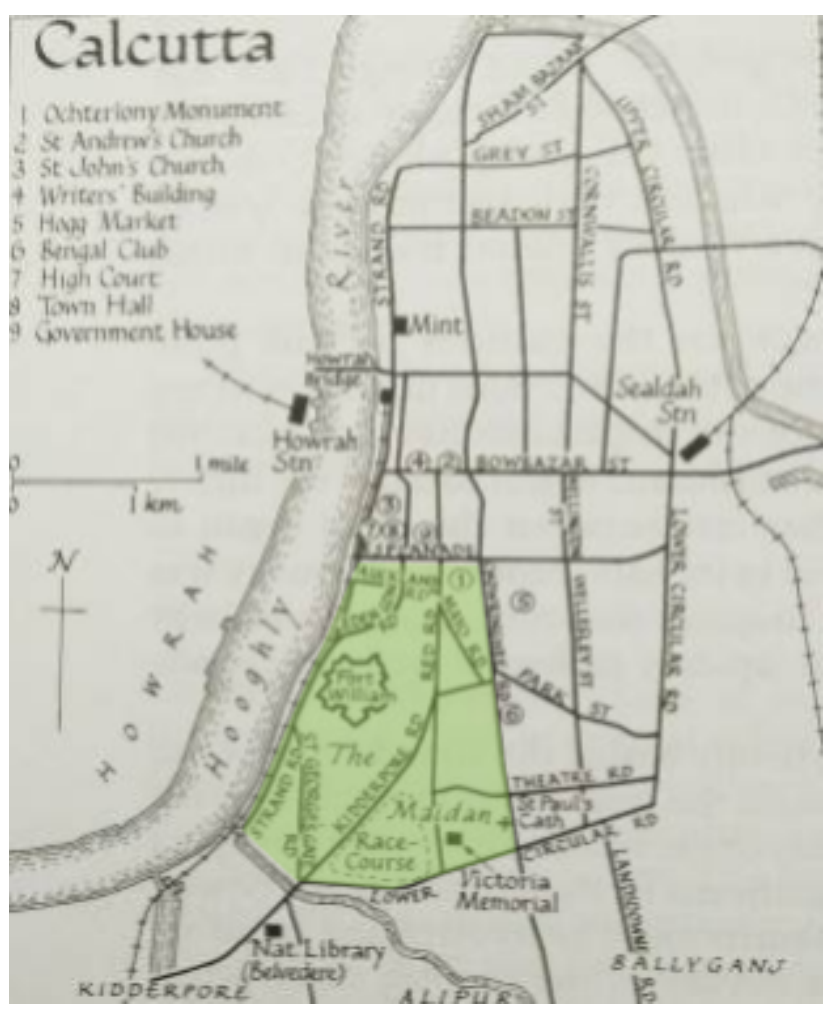
(spatially signified) public domain became instrumental to that process as the prerequisite for large-scale political gathering was an urban public place like the Kolkata maidan.

The presence of the iconic Maidan in the lives and imaginations of ordinary citizens brings forth the question of how has the city- the citizens and the State- re-imagined and appropriated the Maidan over the years as its socio-political role evolved. In parallel situations of other British colonies e.g. the padang in Singapore, we see considerable redefinition through architectural re-articulation which consciously undermine the erstwhile colonial hegemonic spatial expression. The paper would trace the tendencies to which Kolkata has limited herself in re-imagining this heterogeneous space as a socio-political arena.

\section{The Architectural Delineation of the Maidan Limits}

The maidan as a former centre-piece of British spatial expression of authority is appropriated by diverse uses but the edges can be read as a built record of the city's tryst with colonial rule for two hundred years. Evolving from a strictly Palladian palette to a more accommodating Imperial Indo-Saracenic, the continuity of colonial vocabulary is only rarely broken by modern buildings.

Figure 2. Map of Old Calcutta by Simon Winchester (Morris 2005)

The few concrete high-rises that break the monotony could be credited to the modernist zeal of early decades of independence e.g. the Chatterjee International Center (24 floors) built in 1976. Slowly catching up with neo-liberalist 
tendencies the maidan is now a part of a grand Kolkata riverfront urban design scheme which aims to 'recreate London'. One of the newer additions to the maidan skyline is the 42, located between the Tata Centre and the Jeevan Sudha buildings in Chowringhee, still under construction. The southern limits are marked by the extensive site of the marble-clad Victoria Memorial- the indo-saracenic British answer to the Mughal Taj Mahal, connected axially to the east with the neo-Gothic St. John's cathedral.. On the east running from Esplanade in the North to the cultural complex zone in the South is the Chowringhee promenade with arcades, Art-Deco cinema houses, museums, hotels, commercial and cultural centres. To the north are the Raj Bhavan (former Viceroy's house) and BBD Bagh (formerly Dalhousie Square) with the Mohakoron or seat of Government (formerly Writers' building, St John's church, St. Andrew's church- as vestiges of the European town. The western edge is marked by commercial houses along Strand road. Also to the north is the famous Eden Garden stadium- where the British game of cricket was first introduced in the subcontinent, only to be popularly consumed in epic ways later.

\section{The Alien Idea of a Civic Open Space}

The introduction of the Western notions of public civic space in India as part of colonial-rule induced modernization process must be discussed with the idea of modernity as a heterogeneous negotiated experience, moving away from a Euro-American centric narrative. To deliberate on the concept of the public I refer to Sudipto Kaviraj's article dealing with spatial concepts in Kolkata.

The standardized and orderly colonial city posed a conceptual antithesis to the countryside and even the pre-colonial Indian cities. Kaviraj has located the origins of the Western concept of public space in the eighteenth century in a capitalist-democratic context to mean commons with associations like universal access and openness (Kaviraj 1997). William J Glover talks about the idea of public space as a municipally owned urban land as well as a domain of political engagement (Glover 2007). Legal coding of public and private properties was the outcome of sustained urbanization in Europe, supervised by municipal institutions, which also in turn regulated public life, codifying and protecting variable rights, thus engendering eventually a contested domain. The same was applied to the European colonies in due course and thus gained worldwide prevalence.

The idea of rights in the Indian context was a complex socio-cultural phenomenon based more on one's social position, caste and birth than the homogenous and identity-less ideas of universal rights. However socially-agreed concepts of commons and even of common responsibilities existed but, to quote Kaviraj, did not share characteristics like a recognizable source, proper authorization, impersonality, legality, state sanction,..., nor did it carry the no less crucial negative feature of being distinguished from private (Kaviraj 1997). The idea of universality is particularly crucial in its absence as access and rights were encoded in strictly discriminatory social norms.

Through constant surveillance or intervention, the colonial administration had, through a system of sign-s and signifiers, constructed both a physical and conceptual realm where, as Kaviraj puts it, distinctly 'Weberian intelligence acting through the agencies of the State, kept the rules, governed conduct and imposed restrictions, without which the minimal precarious order of modern life threatened to dissolve into chaos' (Kaviraj 1997). Elaborating on this distinction here is important as conceptually, the colonial city, and particularly the maidan as a spatial boundary, held a disciplinary role in the minds of the indigenes. This restricted-access open space was then a site of reinforcement of the conceptual distinction between the two ends of the power relation. The maidan space was heterotopic- a tool for the power structures to exert authority.

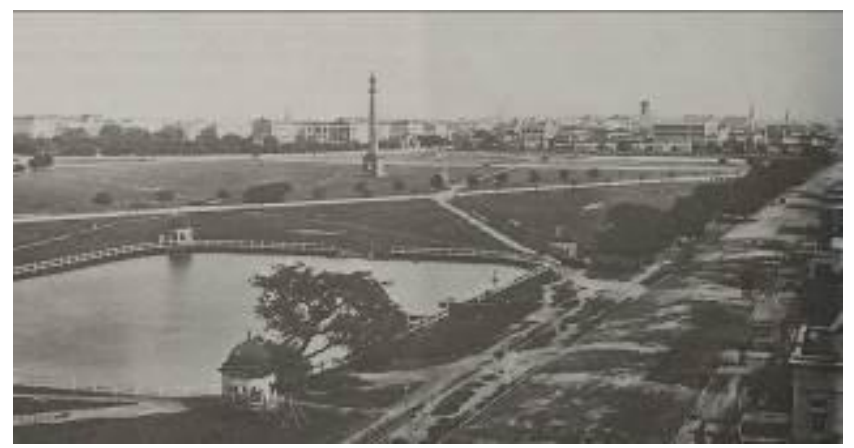

Figure 3. The maidan crisscrossed by wide avenues with Shahid Minar (formerly Ochterlony Monument) in the background (Source: Simon Winchester (Morris 2005))

Pre-colonial urban commons or spaces were not necessarily distinct physically, though possibly resembling in parts the chaos of medieval European cities. But the codification of legality and rights in the colonial civic spaces put into sharp focus the comparative informality of the native urban space counterpartsdeemed, as Glover says, indicative of a faulty society 'lacking in civic spirit' (Glover 2007). This deliberate attempt to not draw parallels between Indian and European spaces has been discussed by Swati Chattopadhyay as the colonial uncanny. She says that the representations of Kolkata at this juncture bears traces of anxiety generated by slippage between desire and experience, the Freudian repression of likeness, familiarity that may not be acknowledged, that marked the passage from picturesque paintings to health maps (Chattopadhyay 2005).

The Western (Hegelian) conviction that the Indian worldview was enamoured with myths and imaginations as compared to a Western objective viewpoint, Chattopadhay says, prompted a specific way of depiction of colonial landscapes. The Company and privately commissioned paintings and later photographs often reinforced the (orientalist) idea of the other. The maidan with the neoclassical facades, even as incorrect imitations, was an image constructed as a contrast- a civilizing presence- 
amidst the 'pathological native world of disease, wilderness and darkness' (Chattopadhyay 2005). Or to 'innocent curious European eyes' it was comfortable disciplined familiarity putting in contrast the novelty and chaos of India. For the European visitors the first glimpse of this world was the wild uncivilized Sagar Island in the Gangetic delta which gave way for the reassuring view of the Kolkata port and Western architecture lining the maidan along the Hooghly. The native squalors, not picturesque as an aesthetic category, were kept well hidden from the European experience as well as representational documentation. The maidan lined with the fine buildings was the extent of the European imagination. To paraphrase Chattopadhyay here, to early European visitors, the white town was the maidan surroundings while the black town was 'seemingly situated somewhere beyond', though socio-economic interdependencies prevented actual insularities.

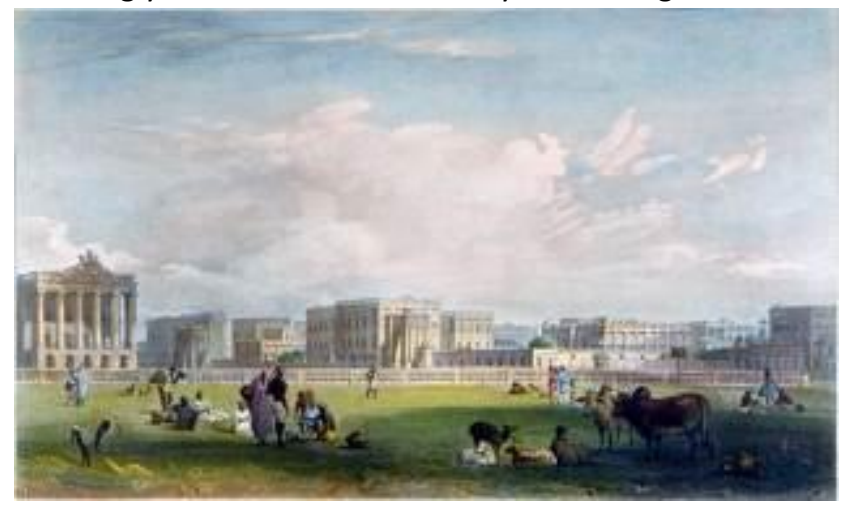

Figure 4. Hand-coloured lithograph of Esplanade Row from maidan by William Wood in 1829 (Source: under public domain from hindoostanrevisited.com)

\section{The Rise of Nationalism and the Idea of Public Sphere}

The idea of a modern public sphere losing a politically critical agency to that of passive consumption is contested by Appadurai. Complex power and knowledge relationships in the postcolonial site of India, he asserts, generates a (petty) bourgeoisie public sphere still genders public discussions as consumers are not 'merely objects and recipients but actors and agents' (Appadurai \& Breckenridge 1995). This examination of public tendencies of appropriation of a colonial space is based on the hypothesis that, in the Indian postcolonial condition particularly, 'cultural improvisations of subaltern groups can involve resistance, co-optation and critique of commodified master forms.' In the paragraphs that follow the attempt would be to trace how a colonial spatial bequest- a symbol of Western capitalist Imperialist presence- is imagined and appropriated in popular public culture and in the process look for the experience of (postcolonial) modernity as an 'involvement of complex forms of subjectivity, agency, pleasure and embodied experience.' (Appadurai \& Breckenridge 1995)

The British introduction of Western ethos when internalised by the modernist literate Indian elites eventually generated an ambiguous modern public sphere in Indian minds. The notion that the state of colonial subjugation could be contested by rational argument or by political dissent necessitated the construction of the idea of the homogenous public. In his remarkable essay 'Is There an Indian Way of Thinking?' Ramanujan elaborates on the Indian openness to a multiplicity of possible ways of approaching a problem. The Indian way has been throughout history that of slow assimilation. The conceptual conflicts between the two ways urban spaces were conceived- the Western notion of universal access, behaviour-controlled, legally public space and the Indian notion of space being sacred or profane, with the rights to commons being socially-encoded, led to a unique negotiated modernity, as experienced by the Western educated Bengali elite. The peculiar configuration produced a discourse when the conceptual mapping of the indigenous inside/ outside was superimposed with the Western coding of public/private. The outside, tamed by civil order, Kaviraj claims, was however the perceived site of modernization- indicative of a world of freedom from orthodox restrictions.

The scene in Aparajito (The Unvanquished)- the second part of Satyajit Ray's Apu Trilogy- where a young Apu, away from his family in the countryside, is struggling to find his footing in the big city of Kolkata as a young student slowly develops an emotional distance with his mother and gets his first tastes of freedom- a respite from all the struggles of his humble rural origins. In the scene he is lying with his classmate on the Hooghly banks along the maidan and daydreams. As a sign of freedom, the maidan area appears in Ray's another movie Parash Pathar, where the protagonist, who has found sudden wealth, escapes from his humble dingy abode and takes a ride in his new car through the wide avenues cutting across the green expanse of the maidan- symbolically conveying his new-found access to the recreational grounds for the relatively privileged.

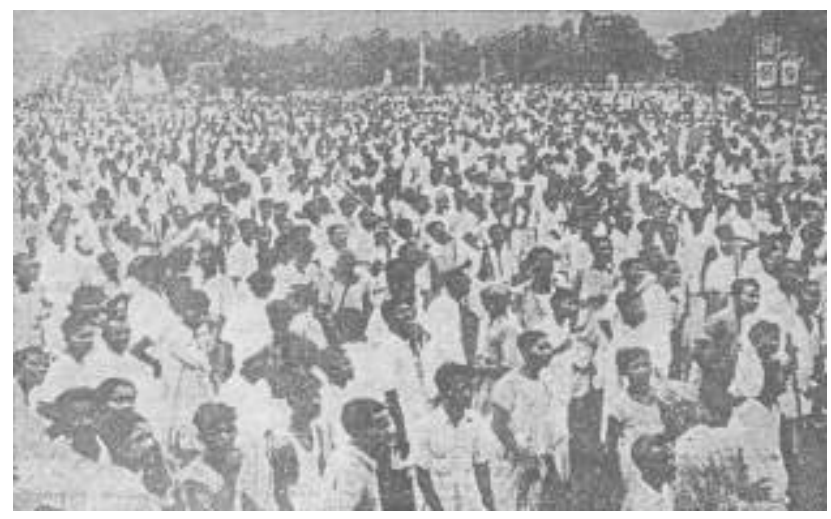

Figure 5. Newspaper photograph of a predominantly Muslim crowd assembled at the foot of the Ochterlony Monument (now Shahid Minar) in Kolkata, to attend a Muslim League meeting on the Direct Action Day16 August 1946 (public domain)

European plazas were essentially large gathering spaces which also served as a site for the political display of State power in front of large crowds who gathered as recipients of the spectacle 
(Kaviraj 1997). The Mughal durbar spaces operated along similar lines of display of authority. The rise of nationalism engendered a requirement of political gatherings. The protopolitical public, then recently having gained a homogenous identity as the subjugated (as against their erstwhile heterogeneous community identity) constructed a public sphere to facilitate political dissent. The physical spatial need for this new entity was provided for in the colonial civic domain. The initial meetings held in public buildings like libraries, town halls or temples slowly escalated to large gatherings in open public spaces- the maidan being a foremost site of political demonstrations. These acts signified a 'daring inversion of spatial symbolism' (Kaviraj 1997). Kaviraj writes that 'the space around the Ochterlony monument, meant to be a great symbol of colonial remembrance and authority, was turned into a privileged site of popular public meetings by nationalist parties.

The maidan even today would be the culminating destination of all political processions- the spectacle through which the public claim rights over civic spaces. This trend continues as the neo-liberal condition has produced what is called the political society (Chatterjee 2005) which gains access to resources using political leverage in the democratic system. The activity pattern and the appropriation of the maidan is distinctly petty bourgeoisie- the early morning strollers, the midday crowd of office-goers, the patrons of the fairs, the numerous sports clubs and recreational clubs- all indicate a middle-class appropriation- in keeping with the post-independence trends of bourgeoisie control of civic decisions. However on the days of political demonstrations the space is occupied and belongs to the under-privileged even today 'to mark some episode of defiance' as a 'spectacle of inversion' (Kaviraj 1997)

\section{Aesthetics and Socio-political Aspirations}

Girish Chandra Ghosh, in 1863, writes about the colonial city as having 'streets smooth as bowling-greens, wide, dustless and dry, where even the lampposts seem to be weekly varnished.' (Morris 2005) The middle-class, Western educated and Enlightened, nurtured a deep appreciation for the ideals of Western civilization- and particularly those of human rights, equality and democracy may have been instrumental in the construction of the Indian nationalist consciousness. Being in close contact with the colonial rulers they formed the bridge between the rulers and the ruled. The richer indigenes did in fact in most cases opt for a re-hashed neo-classical palette for their palatial mansions. From zamindar mansions to relatively modest houses in the older native town show a pronounced inclination for a neo-classical façade, though the internal layouts would not necessarily be as faithful. When the colonial mercantile interests evolved into Imperialist tendencies, the elite middle-class contributed to the municipal decisions as representatives of native subjects of the Crown.

The colonial part of the city was a repertoire of neoclassical, neo-Gothic, Art Deco and later Indo-Saracenic styles. In the European worldview the disciplined urban environment 'held out the promise of reshaping the very core of society' while the neoclassical palette stood for the core principles of Western civilization. The predominance of (petty) bourgeois opinions in municipal decisions has eventually shaped our cities, as opined by Partha Chatterjee in his article 'Are our cities becoming bourgeois at last?'. Even after independence the civil servants were primarily the Western educated middle-class. Aesthetics, as Rancière puts it, is a redistribution of the sensible (Rancière 2004) and here we could be curious if it was conviction with or nostalgia for Western values that made the intelligentia celebrate the trope of Western vocabulary in the maidan area. Resistance in the post-colonial condition took the form of rapid renaming of all the familiar colonial spaces. Most of the colonial roads and spaces underwent a conscious change of name in favor of national leaders of the independence struggle, fueled by nationalist zeal in the years that followed independence. However even seventy years after independence in the public memory the spaces around maidan continue to be identified by both sets of names.

With the underprivileged masses emerging as a political class a demand continues to be made on the State for allocation of resources. Registering insubordination by the underprivileged through occupying a contested public space, is according to Kaviraj, an act of token resistance against a condition of inequality. The neoliberal State throughout the world, to lure in capital has to promote a (Western) image of efficiency. The initiatives to clean-up the image of Kolkata could be read as similar attempts. The State promotes Eurocentric visions for the city, fuelled by formal visits of officials and politicians to London. The scheme incorporates the introduction of prominent visual signs including recreation of the London Eye on Hooghly river banks and other features of the Thames riverfront development.

The idea of public space universally is a contested domain with multiple claims to scare resources. The poor appropriate every vestige of public land ranging from roads, footpaths to vacant lots as a desperate measure for living and livelihood- read here as a resistance and political negotiation. Kaviraj claims that the notion that Kolkata could turn into London is an 'increasingly untenable narrative' as the ground conditions are of a negotiated experience. Realization of a Euro-centric aesthetic in an urban scale presupposes wide-spread awareness and acceptance of Western concepts of civic, public and private realms. In our context even if we consider aspirational aesthetics, the tendency is to generate juxtapositions and hybrid aesthetics (Pal 2016). The iconic maidan, with the current timid steps of introducing new high-rises, along with the pre-existing modernist concrete buildings, European revivalist architecture etc is a repository of images of the city's eventful past and hybrid present - the 'heterogenous temporalities' that signify our condition of modernity. Dipesh Chakroborty describes our present 
epistemology as 'everywhere at every historical moment from the past up to now' (Chakrabarty 2000). As designers of built environment we could be speculative and optimistic about this condition where the challenge would be to respond to and create architectural aesthetics true to all our simultaneous notions, allegiances and aspirations.

\section{References:}

Appadurai, A 1996, Modernity At Large: Cultural Dimensions of Globalization (Public Worlds, Vol. 1), University of Minnesota Press.

Appadurai, A \& Breckenridge, CA 1995, 'Public Modernity in India', in Consuming Modernity: Public Culture in a South Asian World, U of Minnesota Press, Minneapolis.

Chakrabarty, D 2000, Provincializing Europe: Post colonial thought and historical difference, Princeton University Press, Princeton.

Chatterjee, P 2005, Politics of the Governed, The: Reflections on Popular Politics in Most of the World, Orient BlackSwan Pvt. Ltd.

Chattopadhyay, S 2005, Representing Calcutta: Modernity, Nationalism, and the Colonial Uncanny, Psychology Press.

Kaviraj, S 1997, 'Filth and the Public Sphere: Concepts and Practices about Space in Calcutta', Public Culture, pp. 83-113.

Morris, J 2005, Stones of Empire, Oxford University Press, New York.

Pal, S 2016, 'Politics of Urbanscape: Transfiguring the Image of Kolkata', International Conference on Emerging Trends in Engineering, Science and Technology (ICETEST - 2015), Elsevier.

Ramanujan, AK 1999, 'Is there an Indian Way of Thinking? An Informal Essay', in V Dharwadker (ed.), The Collected Essays of A. K. Ramanujan, Oxford University Press, New Delhi.

Rancière, J 2004, The Politics of Aesthetics, Continuum International Publishing, London. 